\title{
Prospects for the implementation of the risk management department in agricultural organizations of Russia and their interaction with the accounting system
}

\author{
Ksenia Burtseva ${ }^{1, *}$ and Aleksandr Alekseev ${ }^{2}$ \\ ${ }^{1}$ Don State Agrarian University, Krivoshlykova str., 24, Persianovskiy set., Russia \\ ${ }^{2}$ Moscow State Institute of International Relations, Vernadskogo ave., 76, Moscow, Russia
}

\begin{abstract}
This article discusses the urgent issue of the importance of integrating and using a risk management system in the work of modern agricultural enterprises. During the study, a review of the risk management system was conducted, its advantages and main stages of implementation were noted, and the conditions for its effective functioning were described. The study contains a list of measures, the implementation of which will optimize risk management in agricultural organizations. The necessity of using a risk-based approach in the preparation of accounting and management reporting as a source of information base for the risk management system is established.
\end{abstract}

\section{Introduction and theoretical part}

In a market economy, business entities independently determine the areas of activity and ways to achieve strategic goals within the framework of the current legislation. Entrepreneurial activity is carried out under the influence of various risk factors, and the vitality and the final financial result of the activities of any enterprise depend on the ability to make and implement managerial decisions.

Agriculture in the Russian Federation is one of the most prospective and fast-moving sectors of the economy, but the organization of this industry is also subject to a large number of risks and adverse circumstances [1]. The ability to manage risks becomes a competitive advantage of a modern enterprise. Risk management is a sphere of management activity, the object of which is risk, and the task is to identify and evaluate various situations that arise under the influence of adverse factors.

Risk management should not be considered as a one-time phenomenon, it should be a combination of regular targeted actions that form a single risk management mechanism integrated into business process of the organization [2].

The primary task of risk management is to identify situations of uncertainty and potential risks. The risk identification stage makes it possible, through a qualitative analysis of various information, to determine the range of threats to the enterprise that can cause

* Corresponding author: ksenbyrts@mail.ru 
damage [3]. It is necessary to take into account both internal factors (financial soundness of an enterprise, investment attractiveness, competence of personnel, marketability, etc.) and external (economic and political situation in the country, financial soundness of counterparties, level of supply and demand in the market, natural and environmental factors of the territory, the emergence of innovative production methods, etc.). Analysis of the conditions in which the organization operates leads to the formation of the idea of possible threats.

First of all assessment of the impact of risks makes it possible to identify the types of risks that can be mitigated and managed. This is the subject of a risk management system [4]. Risk assessment is carried out by quantitative analysis and ranking of risks according to the severity of the consequences of their implementation. it is common to refer to the following levels:

- modest losses;

- high losses;

- critical losses;

- devastating losses.

Modest losses will not be able to affect the financial stability of the organization significantly, unlike high, critical and devastating ones, the implementation of which can lead to loss of financial independence and bankruptcy. Each organization determines the quantitative values of the given levels of financial losses independently, focusing on its resources, goals, profitability of risky actions, etc. An important condition for this is risk managers' clear understanding what risk the organization is dealing with.

Implementation risk is one of the most significant for agricultural organizations regardless of the scale of business. Its effect is manifested in the implementation phase of finished agricultural goods. A decrease in expected sales revenue is caused by various elements:

-competitive activity;

- fluctuations of supply and demand;

- increased costs for logistics and storage;

- loss of product quality due to improper storage, packaging, transportation;

- short sales due to short shelf life;

- artificial understatement of purchase prices by intermediaries, etc.

All of them ultimately lead to lower sales prices per unit of output. Price risk is activated. Unforeseen price reductions for agricultural products deprive the organization of the projected level of income, while the costs of its production, as a rule, have already been made. Thus, the selling price is a key indicator affecting the profitability of the agricultural enterprise. For example, in crop farming, obtaining a high yield, creating reserves and arranging insurance against adverse weather conditions do not guarantee high profit on the basis of product sales, since the actual selling price of a unit of product can be significantly lower than the budgeted for the enterprise.

Risk response strategies are developed by comparing the level of risk and expected profitability. When choosing a risk response strategy, one should rely on the following rules: risk dimension should not exceed capital stock; it is not advisable to risk much for the sake of small gain; the consequences of risk exposure should be calculated. Leading strategies are risk attachment and risk avoidance [5]. The degree of acceptability of risk attachment is obtained by calculating the maximum size of the estimated loss in the implementation of each risk in comparison with the capital stock of the enterprise, as well as the amount of equity.

There are also such strategic options as risk diversification and delegation, involving the involvement of counterparties, insurance companies, the creation of their own target reserves, the adjustment of the project (in order to reduce risk), the distribution of resources 
in several directions, etc. The choice of risk management strategy is based on the experience of managers, attitude to risk and it is also based on the strategic goal of the organization.

In the decision phase on risk management methods, the enterprise summarizes the results of the analysis and draws up an action plan to reduce the probability of occurrence of identified adverse factors or eliminate their effects [6]. At the same time, it is necessary to take into account not only the negative impact of risks, but also the challenges that are offered for the company in new conditions. External and internal threats are a kind of way to stimulate activity and economic growth. This is especially true for the current economic situation. Since any result obtained in the process of activity, positive or negative, can be regarded as a helpful experience, as in the first case this makes it possible to achieve your goal (to make a profit, maintain market share, modernize the process, etc.), and in the second case to avoid possible mistakes in the future.

At any stage of risk management and in the implementation of any response strategy, it is necessary to monitor the progress of the process, which will make it possible to adjust management decisions in accordance with changes in the situation. The main monitoring tool is the information received by the organization managers.

\section{Ways to organize a risk management process}

Organizations create special structural units focused on the identification, analysis and assessment of risks. The use of modern information technology can significantly simplify the risk management process. Existing plans of action are automated and implemented in software to reduce the labor costs of employees of the risk management unit [7]. The ability to take into account many factors in the process of modeling the outcomes of a risk event accelerates and facilitates risk management, helps to reduce or eliminate risks.

Another prevalent way to manage risk is to attract professional business consultants employees of consulting firms. Carrying out a deep comprehensive analysis of the client organization, consultants develop recommendations on resolving issues arising in the economic, financial, legal, industrial and other fields of activity.

It should be noted that the involvement of business consultants, the purchase of specialized programs, the formation of a risk management unit involves significant costs. In Russian agricultural organizations, risk management is usually random. Analysis and assessment of investment or project risks are more widely used when it is planned to carry out construction or acquisition of a new facility, reconstruction of production or its diversification, etc. In agriculture, risk analysis is rarely used, mainly by large agroindustrial holdings by attracting third-party specialists [8]. Small and medium-sized business entities do not manage risk at all, or use the simplest and least costly methods. It is logical that, as a result of the lack of proper attention to risks, organizations suffer losses, and in some cases cease to function. Table 1 presents the dynamics of profitable and unprofitable agricultural organizations, compiled according to the financial statements for the period 2017-2019 [9].

The ability to respond quickly to changes in the environment of operation is an advantage of any organization, regardless of scale and scope of activity. Creating a risk management system, analyzing them, tracking fluctuations in indicators and uncertainties contributes to the rapid adoption of decisions to overcome various adverse events successfully. 
Table 1. Structure of profitable and unprofitable agricultural organizations

\begin{tabular}{|c|c|c|c|}
\hline Number of profitable organizations: & 2017 & 2018 & 2019 \\
\hline thousand units & 3,8 & 3,6 & 2,9 \\
\hline as a percentage of the total number of organizations & 76,3 & 74,3 & 80,4 \\
\hline Amount of profit, million roubles & 243459 & 300015 & 302803 \\
\hline Number of unprofitable organizations: & & & \\
\hline thousand units & 1,1 & 1,3 & 0,7 \\
\hline as a percentage of the total number of organizations & 23,7 & 25,7 & 19,6 \\
\hline Amount of profit, million roubles & 72704 & 95360 & 143003 \\
\hline
\end{tabular}

\section{Concepts and factors of an effective risk management system}

It is important to formulate important concepts that should be followed when setting up the work of the risk management unit in the structure of an agricultural enterprise.

1. The desire to mitigate the number of potential risks, to minimize the probability of their implementation. This will reduce their impact on business results. The threat reduction strategy involves measures to prevent the occurrence of adverse events, which is more effective than efforts to eliminate the negative consequences after their occurrence (working under prepayment agreements with customers, occupational health and safety compliance in the production process, insurance, systematic maintenance and inspection of equipment, etc.

2. The need to ensure the maximum expansion of the objects involved in risk management (structural units, types of products, property assets, lines of business, economic relations with counterparties, etc.). This will reduce uncertainty in the management of the organization. Since all the spheres of entrepreneurial activity are imperilment, the inclusion of a greater number of various objects in the sphere of attention of the risk management service will ensure the high quality of the results of its work. When implementing this provision, it is necessary to measure the labor coefficient, expenditure of resources and practical benefits. Contingency rundown also helps to increase the realism of forecasts for the future development of the organization.

3. The unambiguity of the strategy for the organization to accept only justified risks. Risk management makes it possible to predict the development of the situation, identify adverse factors and problems that may cause financial losses. The forecast illustrates possible alternatives for the development of the consequences of a managerial decision, as well as future conditions of the enterprise under the influence of the identified adverse factors in quantitative indicators of financial and economic activity.

The risk management system should ensure prompt response to negative changes in the real situation (increasing the probability of risk, the emergence of new risk factors, the implementation of risk and cases of uncertainty). The ability to receive timely information about changes in the organization's position increases the speed of decision-making and the adjustment of the adopted risk management strategy. The main source of such information is accounting (financial) and management reporting. Enterprises interested in the information received from the accounting and analytical system today want to know what will happen to the business tomorrow, how effective the implementation of the new investment project will be, how popular the product line will be, the share of production of which goods should be increased, how the advertising campaign will increase sales.

Accounting records all the facts of economic activity and makes it possible to get real information about any changes in property and liabilities in the generated reports. It is necessary to organize close interaction of two systems of accounting and risk management to improve the management system and ensure its effectiveness directly in the field of risk 
management. This will be facilitated by the identification, classification and evaluation of business transactions associated with risk situations, as well as the ranking of accounting objects, the cost of which is affected by risks.

Possession of impersonal data, detailed in accordance with the needs of the user, will make it possible to manage not only individual business processes of the organization, but also make management decisions at micro and macro levels. It is important to emphasize the necessity and expediency of sorting the received accounting and analytical information according to the criterion of importance for management purposes, highlighting the most significant and reference data. This will be achieved by the functioning of a flexible communication system between structural divisions of an agricultural organization.

This approach provides an opportunity to assess the impact of risks in the future, which is especially important for agricultural enterprises with their long production cycle [10]. Conclusions about the achievement of the goals are based on the analysis of deviations and inconsistencies of planned and actual indicators. In practice, methods are used to compare the relative and absolute indicators of the actual results of the current period with the planned one, as well as with the actual indicators of previous periods.

Organizations develop their own KPI (key performance indicators). KPIs make it possible to judge the results of a particular unit in achieving common strategic and tactical goals. Key indicators can be of two types:

- showing results at the end of the reporting period;

- displaying process management capabilities during the reporting period.

Both of these make it possible to identify and evaluate the impact of risks on the activities of an economic entity. The first one helps to create measures and reserves to prevent a high level of risk in a strategic perspective, the second one helps to minimize the negative effects of ongoing risk management. Both groups of indicators are formed on the basis of accounting and managerial accounting data, as the main system for collecting, registering and processing information on business transactions. Monitoring KPI of an agricultural organization in real-time mode makes it possible to respond in a timely manner to a signal about a problem.

An example of generally accepted KPIs in the field of control and increasing the efficiency of the financial and economic activities of an enterprise are: liquidity ratios, profitability, financial independence, capitalization ratios; turnover ratios of receivables and payables, inventories; financial and operating cycle, etc. [11]. The following indicators can be called specific KPIs of agricultural enterprises: average daily weight gain of poultry; feed consumption per kilogram gain; livestock safety; yields per hectare; ripening period; the number and periods of delays in shipment of finished products, etc. All these performance indicators will make it possible to evaluate the productivity of each unit, type of product, operation, as well as identify the "problem areas" and areas of risk situations. This is necessary to ensure the balance of the entire production process.

It is also important to build a breakeven model. This will make it possible to determine the boundaries of the volume of products that ensure the profit of the agricultural organization, which correspond to the limits of tolerance of the risk level and will demonstrate the measurable goal for achieving efficiency (as well as options for changing profitability with a decrease or increase in productivity). The reported financials will make it possible you to determine the critical values of KPI indicators and the stock of financial robustness of the enterprise.

4. The analysis and assessment of risks in order to ensure the quality of management decisions. The continuity of the enterprise determines the influence of operational continuity of the impact of risks and situations of uncertainty on the results. Accordingly, the process of identifying, analyzing and evaluating risks, implementing and monitoring a 
risk response strategy to maintain high efficiency should also be ongoing. In addition to continuity, it is important to observe the following factors:

- a system approach to risk management;

- economic assessment and positive effect of the chosen risk response strategy;

- work with verified information about the situation of the organization and the external environment;

- inclusion of risk management in the general organization management system;

- regular training of employees of the risk management department.

The implementation of these concepts in establishing a specialized department for risk management in the structure of an agricultural enterprise will ensure its economic efficiency, consistency and rationality.

\section{Conclusions}

Risk management opens up new opportunities for agricultural organizations. The regulated risk management process makes it possible to find a strategy for dealing with threats. In the existing set of alternative options, managers receive tools for the most correct decisions based on the results of in-depth analysis. Creating a risk management system in an organization will entail changes in the work of financial and economic units. The implementation of a risk-based approach in the formation of accounting and management reporting will allow enterprise to monitor the fluctuations of important indicators in the structure of the property and liabilities of the organization, and the reporting itself will become the basis of the study of risk managers.

Thus, in a context of economic instability, agricultural enterprises must have a system of prompt response to market threats and strategies to prevent, minimize and eliminate negative consequences. The risk management system is of great importance for ensuring financial stability and sustainable development of agricultural enterprises.

\section{References}

1. L.I. Khoruzhy, Yu.N. Katkov, V.I. Khoruzhiy, K.A. Dzhikiya, E.I. Stepanenko, Astra Salvensis, VI, Special Issue, pp. 835-845 (2018)

2. G.E. Krokhicheva, E.L. Arkhipov, M.Yu. Bazdikyan, A.V. Istomin, Internet journal "SCIENCE", 4 (2017)

3. S.M. Vasin, V.S. Jesters, Enterprise risk management: a training manual (KNORUS, 2018)

4. O.V. Konovalova, S.S. Feshin, Economics. Taxes. Right., 6, p. 54-61 (2017)

5. D. K. Van Horn, D. M. Wachovich, Fundamentals of financial management (Williams Publishing House, 2016)

6. V.B. Ivashkevich, N.A. Ermakova, A.A. Elakova, The development of managerial accounting and analysis in a crisis state of the enterprise economy: monograph (Kazan, 2014)

7. V.M. Bezdenezhnih, Designing an organization's risk management systems, [Electronic resource].

Access mode: https://bstudy.net/650957/ekonomika/proektirovanie_sistem_upravleniya_riskami_org anizatsii.

8. N.V. Kuchkovskaya, Modern science: Actual problems of theory and practice. Series: economics and law, 7, pp. 26-32 (2018)

9. Bulletin "Key indicators of agriculture in Russia in 2019" [Electronic resource]. - URL: https://gks.ru/folder/11110/document/13276 
10. S.E. Egorova, N.N. Kistaeva, Accounting. Analysis. Audit, 5, pp. 30-39 (2017)

11. A.D. Sheremet, E.V. Negashev, Methods of financial analysis (INFRA-M, 2012) 